\title{
Experiencias de familias en pobreza en el sur de Mérida, Yucatán. Explorando posibilidades del Trabajo Social en el contexto neoliberal
}

\section{Experiences of families in poverty in the south of Mérida, Yucatán. Exploring possibilities of social work in the neoliberal context}

\author{
SILVIA MONTEJO-MURILLO. \\ Doctora en Ciencias Sociales por la Universidad Autónoma de Yucatán. \\ Maestra en Trabajo Social por la Universidad Nacional Autónoma de México. \\ silvia.montemuri@gmail.com
}

Resumen: El objetivo de esta investigación fue analizar la pobreza desde las experiencias de dos familias de la colonia Emiliano Zapata Sur II de Mérida Yucatán, con la finalidad de contribuir al quehacer del Trabajo Social desde una perspectiva humanista. El análisis mantuvo un enfoque cualitativo que se colocó dentro de un paradigma interpretativo y se apoyó de un método fenomenológico. Se utilizaron entrevistas semi-estructuradas y observación participante para obtener durante dos años los datos primarios. Entre los principales resultados se encuentran que los jefes de familia, son quienes palían la pobreza a través de su ingreso y liderazgo. Asimismo, existe un estigma sobre la colonia que la cataloga como "pobre" que influye en su condición. De igual forma, a pesar de que la familia es un sistema, cada miembro experimenta la pobreza de forma particular, necesitando más o menos recursos y satisfactores. Se recomienda para futuras investigaciones, tomar en consideración la "forma de pensar y de vivir" de la familia y de cada integrante, uno de los mayores retos al que el Trabajo Social se enfrenta desde todos sus campos de diagnóstico e intervención, dada la elevada población y la limitación de sus recursos como profesional dentro y fuera de las instituciones.

Palabras clave: Pobreza, Familia, Trabajo Social, Experiencias, Análisis, Discurso, Redes de apoyo, Relaciones Humanas

\begin{abstract}
The main objective of this research was to analyze poverty from the experiences of two families from the Emiliano Zapata Sur II neighborhood of Mérida Yucatán, in order to contribute to the work of Social Work from a humanistic perspective. The analysis maintained a qualitative approach that was placed within an interpretive paradigm and was supported by a phenomenological method. Semi-structured interviews and participant observation were used to obtain the primary data for two years. Among the main results are that the heads of the family are those who alleviate poverty through their income and leadership. Likewise, there is a stigma on the colony that classifies it as "poor" that influences its condition. Similarly, despite the fact that the family is a system, each member experiences poverty in a particular way, requiring more or less resources and satisfiers. It is recommended for future research to take into consideration the "way of thinking and living" of the family and of each member,
\end{abstract}


one of the greatest challenges that Social Work faces from all its fields of diagnosis and intervention, given the high population and the limitation of their resources as a professional inside and outside the institutions.

Keywords: Poberty, Family, Social Work, Experiences, Analysis, Speech, Social Support Networks, Human Relations

\section{INTRODUCCIÓN}

A pesar de las acciones de los Estados para contrarrestar las cifras de personas en pobreza, este fenómeno se mantiene e incluso se agudiza con los años. En 2015, se identificaron a nivel mundial a más de 736 millones de personas que vivían por debajo del umbral de pobreza internacional. Actualmente, alrededor del diez por ciento de la población mundial vive en pobreza extrema y tiene dificultades para cubrir sus necesidades más básicas, como la salud, la educación y el acceso al agua y al saneamiento (Naciones Unidas, s.f.). Como problema social, la pobreza limita o inhibe el desarrollo y la vida del ser humano, al grado incluso de mantenerlo en sufrimiento constante o de causarle la muerte, dejando a la persona sin dignidad y arrebatándole inmediatamente el disfrute de sus garantías individuales y derechos sociales.

Asimismo, este fenómeno ha sido objeto de estudio de varias disciplinas, entre las que se destacan la sociología y la antropología. Desde la sociología, la pobreza es un efecto de mecanismos estructurales de desigualdad. En la antropología, la pobreza es un estilo o modo de vida que adoptan las personas en tal condición para sobrevivir. En una definición más amplia de Amartya Sen, Premio Nobel de Economía, se puede entender como "la privación de capacidades básicas", refiriéndose a estas capacidades como "las libertades fundamentales de que disfruta para llevar el tipo de vida que tiene razones para valorar" (Sen, 2000, p. 114). Así, en otras palabras, se puede decir que la pobreza no es un problema solo de una renta escasa, sino de la limitada oportunidad para ejercer libertades o capacidades.

Considerando a la pobreza como "ausencia de capacidades", es un problema más complejo que solo la medida del "ingreso". Si bien "la renta" es un medio para disfrutar de bienes y servicios que permiten paralelamente el disfrute o gestión de las capacidades de un individuo, es aún más importante analizar con detenimiento cómo se desarrollan estas capacidades, cuáles son y con base a qué son valoradas.

El Trabajo Social, dentro de los aportes y contribuciones que las ciencias sociales han hecho para solucionar este problema, se ha caracterizado por intervenir en los problemas sociales desde las personas que los padecen a través de su práctica. Escuchar diariamente las situaciones que experimentan las personas, es una de las funciones más importantes que el trabajador social realiza. De igual forma, en el Trabajo Social se entendería que el "humanismo" está implícito en la disciplina, sin embargo, en el presente análisis se retoma como una perspectiva teórica y posicionamiento ético imperativo, que el profesional busca cultivar a lo largo de su vida y en su quehacer, como "un estilo de vida humanizado y humanizante" (Ander-Egg, 2011, p. 147) y en el que trabaja de forma colaborativa y horizontal con el agente.

Asimismo, en el caso de México, el Trabajo Social se ha desarrollado por lo menos en los últimos cincuenta años, dentro de un sistema político caracterizado por el asistencialismo (Valero, 1994), una estrategia política que ha exigido respuestas en el corto plazo y que ha derrochado una gran cantidad de recursos, algunas veces, sin una adecuada planeación. Concentrando su labor en el sistema de salud como gestor de las necesidades de los usuarios dentro de los hospitales.

Sin embargo en este mismo país, en donde el Estado del Bienestar se encuentra casi ausente, han surgido nuevas organizaciones de la sociedad civil como una respuesta social ante la exclusión, pauperización y desigualdad producida por el sistema neoliberal, activando espacios en donde el Trabajo Social encuentra áreas de oportunidad de intervención y análisis desde dos niveles importantes: desde lo macro, al observar con detenimiento la naturaleza de las políticas públicas y los programas sociales, así como las dinámicas estructurales que le dan forma al sistema y delimitan la vida de las personas; y desde lo micro, al estudiar las movilizaciones que los actores ahora agentes, pueden hacer para impulsar acciones que les permiten tener un resultado positivo en su historia de vida, en un grado familiar y a escala comunitaria.

Posicionándose entonces desde esta visión es que explorar las experiencias de personas que han sido catalogadas como "pobres", constituye un recurso valioso que permite observar con detenimiento las causas de la pobreza, desmantelar estructuras de poder y entender el estigma que envuelve a los individuos en aparente condición, sobre todo 
escuchar sin juzgar el testimonio personal de quienes han sido señalados por otros grupos. A partir de este análisis, es que el trabajador social podrá incursionar en diferentes áreas y niveles de su disciplina.

\section{ANTECEDENTES DEL "SUR" DE MÉRIDA}

En Mérida, la capital del estado, la cual concentra el 42.66 $\%$ de la población de Yucatán, un $22.9 \%$ de su población (220,724 individuos) se encuentra en situación de pobreza (Secretaría de Bienestar, 2020). Si bien las personas en esta condición pueden estar dispersas en la ciudad, existe una tendencia a que una parte de esta población se concentre en el sur (García y Ruiz, 2011, pp. 129-136), el cual se contrasta de forma significativa con un norte modernizado y caracterizado por "el desarrollo". Esto se puede explicar porque a pesar del "predominio de Mérida como asentamiento de mayor jerarquía dentro del sistema urbano estatal y metropolitano, en el cual se concentra el intercambio de personas, bienes y servicios de todos los niveles y tipos del estado" (Bolio, 2014, p. 37), en este municipio se sigue propiciando un fenómeno histórico de segregación de la población que divide a la población en dos zonas.

"La parte norte de la ciudad ha registrado los menores niveles de ocupación y elevados precios del suelo" (Bolio, 2014, p. 38). La población meridana en general reconoce este espacio como el lugar en donde se encuentra el trabajo y mejores condiciones de vida, que se han dado a partir de las mayores inversiones en infraestructura de la ciudad. El norte está conformado preponderantemente por familias que habitan en lujosos complejos residenciales y que pueden acceder a la enorme gama de comercios y restaurantes modernos, los cuales son sostenidos productivamente en una parte importante por la mano de obra de la gente del sur, la otra cara de la ciudad.

A diferencia del norte, el sur de Mérida está compuesto por familias inmigrantes de otras partes de México y de las periferias de Yucatán, que han construido sus viviendas con materiales de desecho y algunas piedras disponibles en este espacio (mampostería), o bien que habitan casas que se encuentran en obra negra en un terreno que les ha concedido el Instituto de Vivienda del Estado de Yucatán (IVEY). En la mayoría de estas casas, se pueden apreciar fachadas desgastadas y descoloridas por el tiempo y la falta de mantenimiento. Las familias que habitan estas viviendas, regularmente están integradas por niños que cursan en alguna escuela cercana y por hombres y mujeres que se emplean en negocios aledaños o bien se desplazan en el transporte público hacia el norte o centro de la ciudad, para ocuparse en alguna residencia, fábrica o empresa. De esta forma, se puede decir que Mérida, se encuentra dividido y extrapolado en el plano socioeconómico y territorial en dos espacios reconocibles para toda la población, marcados por la desigualdad y que caracteriza a la zona sur como "pobre" en comparación con el resto de la ciudad. En esta zona sur es donde se circunscribe la presente investigación y se encuentran las familias analizadas.

\section{METODOLOGÍA}

El presente estudio tuvo un enfoque cualitativo y se realizó en la colonia Emiliano Zapata II (EZS II), que pertenece al municipio de Mérida en Yucatán, México. La investigación fue de tipo descriptiva e inductiva que se sirvió de un método fenomenológico. "La fenomenología es el estudio de los fenómenos tal como son experimentados, vividos y percibidos por el sujeto social. Husserl, fundador de la fenomenología, acuñó el término Lebenswelt (mundo de vida, mundo vivido) para expresar la matriz de este 'mundo vivido, con su propio significado'" (Martínez, 2006, p. 137). Esta se llevó a cabo tomando como herramienta las historias de vida obtenidas con las entrevistas, lo que permitió estudiar la realidad desde el marco de referencia del sujeto que vive el problema y profundizar en él, para identificar categorías de estudio que son relevantes replantearse en el Trabajo Social contemporáneo, tales como el empleo, la educación, la salud, la vivienda, la alimentación y la agencia social. El estudio fue transversal debido a que se realizó en un sólo momento (Hernández, Fernández y Baptista, 2010) y durante dos años, de 2015 a 2017.

La muestra fue "intencional" (Martínez-Miguélez, 2006, p. 86), seleccionada con base en criterios. Las familias participantes desearon hablar de su vida y experiencias cotidianas. Para recuperar las experiencias se utilizaron entrevistas semi-estructuradas que se transcribieron. Asimismo, se utilizó como técnica la observación participante con la que se recabaron datos y notas sobresalientes durante las entrevistas y los recorridos por la zona. Esta información se contrastó y trianguló con las narraciones producidas en las entrevistas, obteniendo las categorías de análisis. Fueron entrevistados y se convivió de forma frecuente con siete personas, dos de la primera familia y cinco de la segunda, así como con cinco informantes clave de la colonia, quienes recibieron un consentimiento informado y tuvieron la disposición de participar en la investigación. Asimismo, como parte de la perspectiva "humanista", los participantes marcaron las pautas de relación con ellos y se utilizaron pseudónimos para proteger su identidad. 


\section{RESULTADOS}

\section{Origen y formación de la Emiliano Zapata Sur II}

De acuerdo a dos informantes clave, los cuales estuvieron cuando se fundó la colonia, la EZS II comenzó a formarse cuando hace aproximadamente veinte años, varias familias se asentaron en un territorio deshabitado. Los informantes relataron que se desplazaron a esta zona, con la esperanza de conseguir un empleo en Mérida o un lugar de residencia que les permitiera tener mejores condiciones de vida que las que tenían en sus lugares de nacimiento. Con el paso del tiempo, el IVEY les cedió el derecho de terrenos de $5 \times 20$ metros a las familias que los habitaban y habilitó los servicios de electricidad y agua, lo que propició que incrementara el número de habitantes y atrajera a otras personas que se asentaron sin tener un título de propiedad en la zona. Actualmente, la colonia Emiliano Zapata Sur está dividida en I, II y III.

El lugar cuenta con catorce cocinas económicas, tres templos pentecostés, una iglesia bautista, una iglesia adventista y una capilla católica, una escuela primaria, una escuela preescolar, dos tiendas de abarrotes particulares y algunas tiendas de conveniencia familiares. Cerca de esta zona se encuentra también una avenida que ofrece servicios de salud y tiendas de conveniencia.

Las calles principales de la colonia se encuentran pavimentadas, sin embargo, la gran mayoría son caminos de arena. La colonia tiene un parque que tiene acceso gratuito a internet por medio de red inalámbrica; un Centro de Desarrollo Integral que pertenece al municipio; y el Centro de Desarrollo Marista (Cemade) fundado por la Universidad Marista de Mérida.

Por otra parte, en cuanto a la iniciativa política estatal o municipal, si bien se identificaron programas sociales y acciones que buscan satisfacer necesidades básicas como alimentación y gestionan derechos sociales como la educación y la vivienda, estos atienden algunas dimensiones de la pobreza multidimensional, que es el principal indicador que utilizan actualmente los gobiernos de México para medir la pobreza y el cual fue establecido por el Consejo Nacional de Evaluación de la Política de Desarrollo Social (Coneval). Este indicador si bien es un medio para medir el estado actual de desarrollo social y económico de los individuos, éste considera los criterios establecidos por el Coneval y por ende, las recomendaciones de organismos internacionales que financian y condicionan la política social de países con deuda externa como México (Pérez, 2011). Estas "sugerencias" tratan de aliviar los efectos colaterales que trae consigo el neoliberalismo y la globalización. En este contexto y en donde el capital es el recurso por excelencia para el acceso a los satisfactores, la generación de empleo formal continúa siendo una necesidad urgente dentro del país y este municipio, que parece no ser cubierta del todo. Asimismo, considerando las características espaciales de la región, sería necesario explorar la creación de un indicador estatal de medición de la pobreza que retome el fenómeno desde el desarrollo social y humano, al mismo tiempo que considere la cultura de colaboración y participación política que existe en los habitantes del estado.

\section{Experiencias de la familia conformada por doña Greta y don Luis}

La primera familia entrevistada es una pareja que se encuentra en la colonia desde su fundación. Está compuesta por una mujer de 47 años y un hombre de 56 años que son originarios de Candelaria, un municipio de Campeche en México. Ambos manifestaron provenir de un lugar en donde vivieron pobreza extrema, sin servicio de electricidad ni agua y en el que dependían para comer de lo que se cosechara y en mucho, de que hubiera lluvia para recolectar agua y regar los sembradíos. La mujer mencionó que en ese lugar vivió muchas carencias, además de que en la localidad existía alcoholismo, drogadicción y violencia en algunas casas, lo que le hacía recordar un ambiente hostil en el que no quería volver a vivir. La pareja se casó en Candelaria, pero decidió venirse a Mérida porque se enteraron por medio de un familiar de las facilidades que estaba otorgando el IVEY para adquirir un predio en la zona, a quienes permanecieran viviendo por lo menos un año en una casa construida de cualquier material (actualmente la colonia EZS II y aledañas)

El hombre y jefe de este hogar al cual de ahora en adelante llamaremos don Luis, fue el mayor de once hermanos, cuatro hombres y siete mujeres. Creció con su madre y su padre. Él mencionó que la relación familiar "fue buena". Por su parte, doña Greta manifestó haber crecido con su padre, su madre y siete hermanos, tres mujeres y cuatro hombres. A diferencia de don Luis, relató tener una infancia llena de violencia en donde ella y sus hermanas recibían maltrato físico y psicológico por parte de su padre "por ser mujer", además de que su madre repetía esta dinámica con sus hijas. Comentó que fue con la ayuda de una psicóloga de una asociación civil que llegó a EZS II, que empezó a hablar sobre estas experiencias para tratar de superarlas. Asimismo, algunos talleres impartidos por una iglesia católica en la colonia (sobre superación personal), le han brindado apoyo emocional. 
Es que cuando yo nací no me quisieron porque era niña, crecí con mi abuela porque no me querían, me botaron y me recogió mi abuela y después, cuando mi abuela falleció, a fuerza me tuvieron que volver a recoger [sic]. (Doña Greta, ama de casa, trabajadora doméstica eventual, 47 años)

Doña Greta con llanto y tristeza contó este relato, haciendo hincapié durante las entrevistas, que le dolía recordar el pasado y que no quería hablar de él. Asimismo, ella manifestó haber sufrido maltratos por parte de sus hermanos, declarando que uno de ellos quiso abusar sexualmente de ella, situación que no permitió. Señala que al día siguiente de que ella relató este hecho a sus padres, ellos no le creyeron e incluso evadieron el tema, porque "los hombres tenían un lugar predilecto dentro de la familia" (Doña Greta).

Por otro lado, con respecto a sus relaciones familiares y observando esta unidad familiar, a pesar de haber crecido en un contexto de pobreza extrema, la pareja tiene una percepción distinta que marca las relaciones en su familia presente. Doña Greta reconoció que sus experiencias del pasado no le permiten vivir en plenitud. Por su parte don Luis, durante el estudio, se observó que es un hombre tranquilo y relató que dejó el alcohol hace algunos años por decisión propia, "para no desperdiciar el ingreso".

En cuanto a las actividades cotidianas de las familias de origen de ambos, estaban centradas en conseguir ingresos y alimentos, por lo que se integraba a los hijos a temprana edad para conseguirlos, ya sea trabajando en sus terrenos en la milpa, cosechando árboles frutales o bien saliendo a trabajar fuera de la localidad para obtener un ingreso que les permitiera comprar alimentos. En palabras de don Luis: "se vivía para trabajar". Por esta razón, ellos abandonaron la escuela a temprana edad y continuaron con las actividades que sus padres realizaban.

Mi papá era carpintero, no sé a qué se dedicaba mi mamá, teníamos que trabajar, cosechábamos árboles frutales. El terreno en donde se cosechaba era de mi abuelo para mi papá, pero luego mi abuelo lo puso a nombre mío. (Doña Greta, ama de casa, trabajadora doméstica eventual, 47 años)

Mi infancia fue un poco de sufrimiento, a los catorce años estaba trabajando en un barco, me caí en el río, no me ahogué porque sabía nadar, de ahí me fui a Ciudad del Carmen a trabajar de peón de albañil ... sí sufrí mucho cuando era chico, tenía que buscar dinerito pa' ayudar a mi mamá [sic]. (Don Luis, velador, 57 años)
Los entrevistados contaron sus experiencias con nostalgia y reconocen que les hubiera gustado seguir estudiando, pero que debían ayudar a sus padres para poder sobrevivir. "Ir a la milpa y cosechar significaba tener qué comer, pasar unos días sin hambre y un poco de tranquilidad para los días venideros" [sic] (Don Luis). Ambos integrantes de la familia, coincidieron en que trabajar desde edad temprana, no les permitió disfrutar plenamente de etapas como la niñez y la adolescencia. Por ello, una de las palabras que de acuerdo a los entrevistados describe la situación en la que se encontraban es "sufrimiento".

Asimismo, en cuanto a cómo se percibe la pobreza, para esta familia significa "no tener qué comer y no tener condiciones para acceder a alimento". Don Luis comentó que: "La colonia está marginada, pero uno tiene que buscar salir adelante y hay personas que no quieren trabajar, incluso a veces la mujer se emplea y el hombre se mantiene embriagado". Por su parte doña Greta agregó: "Uno se siente marginado, ¿Por qué ellos comen y nosotros no? ¿O el dinero de ellos vale y el de nosotros no? ¿Por qué ellos sí y nosotros no?"

\section{Experiencias de la familia de doña Beatriz}

Esta familia estuvo conformada por siete integrantes: tres mujeres, una de 48 años, otra de 32 años y una de 76 años; y cuatro hombres, uno de nueve meses, otro de dos años, uno de 18 y otro de 15 años. La jefa del hogar es la señora de 48 años que vive con su hija, sus dos nietos, su mamá y un sobrino que adoptó desde pequeño, hijo de su hermana. Este sobrino adolescente tiene 18 años y padece mielomeningocele, una afección y un tipo de espina bífida que no le permite caminar, manteniéndolo en una silla de ruedas. La jefa del hogar a la que de ahora en adelante llamaremos doña Beatriz, fue quien se asentó en la colonia en el año 2000.

Antes de llegar a la actual colonia EZS II, ella vivía con sus padres, con los dos hermanos hombres de los cuatro que tiene, con sus dos hermanas y su hija, frecuentando en la casa de sus padres, al papá de su hija. En ese tiempo, supo que estaba embarazada y se enteró por medio de un conocido, que una persona había abandonado el predio que ahora vive, habiendo la posibilidad de que el IVEY se lo concedieran si lo invadía, por lo que decidió venirse a vivir a esta zona con su hija. Así, empezó a habitar una casa de cartón y láminas que ya existía y comenzó a mejorarla, renovando los materiales de desecho con los que estaba hecha con unos nuevos.

En un inicio, el IVEY no le permitía a doña Beatriz permanecer en el predio, sin embargo, después de un año de 
haberse asentado en él, la institución le brindó facilidades para regularizar la propiedad. Cuando obtuvo la aprobación de esta institución, se informó sobre la situación del terreno, poniéndose al tanto de que no estaba escriturado, por lo que doña Beatriz inició este trámite sin dar un anticipo. La propiedad tiene una longitud de 10 × 20 metros.

Doña Beatriz vivió con sus hijos adolescentes en la casa de cartón y lámina durante un año hasta el 2002, cuando el huracán Isidoro azotó a Yucatán y deterioró su vivienda. A partir de este evento, el Fondo de Desastres Naturales (Fonden) le otorgó dos meses después del meteoro, una pieza de concreto de 4 x 5 metros y un baño que tiene un inodoro y una regadera del mismo material. El baño de $1 \times 1$ metro está construido por fuera del cuarto de concreto y a un costado de la casa de cartón y lámina que ya existía.

En el 2016, su mamá, su hija y su nieto se pasaron a vivir con ella, dejando la pieza hecha de cartón y lámina para cocinar y comer y el otro cuarto de concreto, para dormir y descansar. Asimismo, como el baño estaba muy pequeño, su papá que era albañil, le ayudó a construir un cuarto para bañarse afuera de $1.5 \times 1.5$ metros, hecho de cartones y láminas y a un lado del lugar en donde estaba el inodoro. En los dos cuartos, están todas las cosas más básicas para sobrevivir. En el de cartón y lámina están los vasos, los platos y una mesa que sirve para cocinar y comer, mientras que en el de concreto está su ropa guardada en cartones y tres hamacas individuales.

Posteriormente, a los cuatro años de vivir aquí, su hermana le cedió para su crianza a su sobrino Luis de siete años a petición de doña Beatriz, ya que comentó que "no cubría por completo las necesidades de su sobrino a causa de su enfermedad" y ella consideró que podía hacerse cargo de él. De esta forma, la nueva familia, constituida por doña Beatriz, su mamá, sus hijos y su sobrino vivió en una pieza de concreto, una pieza hecha de cartón y lámina y con un baño, durante siete años, hasta que doña Beatriz reunió dinero, y su papá y su hermano que también era albañil, construyeron una segunda pieza de casa de 4 × 5 metros. Así en el 2016, las siete personas empezaron a vivir en una casa que actualmente está constituida por cinco piezas, tres hechas a base de concreto y dos construidas con cartón y láminas. Los dos cuartos de 4 × 5 metros cumplen varias funciones dentro del hogar, como dormitorio, como comedor y sala, mientras que los baños, el de cartón y láminas y el de concreto y la cocina, se siguen manteniendo como en un inicio.

Con respecto a la dinámica familiar, a diferencia de la primera, esta familia de acuerdo a los integrantes, no tiene un pasado donde haya existido violencia ni carencia extrema en donde desde pequeños hayan tenido que trabajar. Esta familia es originaria de Muna, un pequeño municipio ubicado en el sur de Yucatán que también ha sido caracterizado como un lugar "pobre". Doña Beatriz y su madre manifestaron en reiteradas ocasiones que tuvieron una vida tranquila en su familia. Asimismo, en las narrativas se identificó que en algunos miembros, no existe una perspectiva sobre el futuro, es decir, que viven de acuerdo a las necesidades de cada día, tal como lo muestran los siguientes testimonios:

Estaba estudiando la preparatoria, pero no la terminé, en el segundo año reprobé varias materias y ya no pude seguir. Sí me gustaba estudiar, pero no tengo tiempo porque trabajo de lunes a sábado y luego llegó a la casa con los bebés, ya no me da el tiempo para ir, pero sí me gustaría seguir en una preparatoria abierta. (Hija de doña Beatriz, madre, empleada doméstica, 32 años)

Pues mire, gracias a Dios soy feliz. Ya ahorita no pido nada, porque más adelante no sé si voy a disfrutar o no, con el tiempo me voy y listo. (Mamá de doña Beatriz, 77 años)

Por ahora no tengo metas de vida, en unos años me gustaría trabajar y tener hijos, pero no he pensado cómo le voy a hacer [sic]. (Sobrino de doña Beatriz, 18 años).

Esta idea parece ser parte del sistema familiar que les ha servido para sobrevivir y seguir adelante, pensar poco y concentrarse en el presente es una estrategia de vida que comparten los miembros de esta familia. Por otra parte, con respecto a lo que esta unidad considera como pobreza, la madre de doña Beatriz expresó que: "La pobreza viene siendo que te falte comida, que no tengas nada para comer". Doña Beatriz por su parte manifestó que pobreza: "Es no tener qué comer, en dónde vivir", mientras sus hijos y su sobrino se abstuvieron durante el estudio de hablar al respecto.

\section{Comparando las familias}

En los dos hogares existe hacinamiento, doña Greta y don Luis viven en un cuarto de 4 × 5 metros que es cocina, dormitorio y sala, mientras en la casa de doña Beatriz viven siete personas en tres cuartos que, aunque uno es cocina, sirven para que se desenvuelvan durante el día y como dormitorio. En cuestión de ingreso, a simple vista pareciera que la familia de doña Beatriz tiene una entrada mayor de dinero, de \$8720, en comparación con los \$3488 de la familia confor- 
mada por doña Greta y don Luis, no obstante, este ingreso global disminuye cuando se divide entre los integrantes, resultando \$1246 por persona en la familia de doña Beatriz y $\$ 1744$ por persona, en la otra familia. Otro punto relevante del ingreso es que la mayor parte se destina a cubrir la alimentación, el $80 \%$ del recurso en la primera familia y el $90 \%$ en la segunda, a pesar de que se trate de "rendir la comida".

Ambas familias relataron que se cuece frijol cada dos o tres días y se guarda en el refrigerador para que se consuma en la semana, se comen huevos de manera frecuente en el desayuno y en la comida, acompañado de pan francés, y sólo los fines de semana, las familias compran comida preparada, regularmente pollo asado o "cochinita" el cual es un platillo típico de Yucatán. Asimismo, con respecto al vestido, las personas de las dos familias, se les puede ver usando ropa sencilla que incluso en ocasiones, otras personas les ceden, también se observó que sus casas cuentan solo con los aparatos electrónicos y utensilios básicos para vivir. Es importante señalar que como el resto de Mérida, este lugar es muy caluroso y ninguna de las dos casas cuenta con aire acondicionado, solo con un ventilador de pedestal. La casa de doña Greta y don Luis está pintada por completo, mientras que en la de doña Beatriz solo se encuentra pintada la fachada. En cuanto a las actividades que realizan ambas familias, el hijo de doña Beatriz no asiste a la escuela, mientras su sobrino acude ocasionalmente, a una escuela abierta para adultos. Asimismo, los adolescentes reportaron no ir al cine o practicar algún deporte, mientras que las personas mayores se dedican a las labores del hogar o a trabajar y no reportaron asistir a alguna actividad impartida en los centros de desarrollo, excepto por doña Greta que asiste eventualmente a una asociación civil y recibe personas de una iglesia protestante. Esta es la vida que llevan ambas familias, de consumo limitado, con poca información sobre los programas y proyectos en los que pueden participar y con bajos niveles de educación formal, un caso que es frecuente observar en el resto de las familias de la colonia y que va creando un estilo de vida y una identidad social propios del lugar, porque todos viven igual, nadie es más ni es menos.

\section{DISCUSIÓN}

En ambas familias se observaron ciertos elementos de una "cultura de la pobreza" entre los que se destacan la lucha constante por la vida, bajos salarios, trabajo infantil, ausencia de reservas alimenticias en casa, falta de vida privada y miembros parcialmente integrados a las instituciones (Lewis, 1964). Así mismo, es también un estilo de vida es- tructurado y una disposición razonada con mecanismos de defensa (Lewis, 1964), que les ha permitido vivir de generación en generación y que se vive de forma diferenciada entre los integrantes de cada familia. Por ejemplo, doña Beatriz y su hija, así como doña Greta y don Luis, que son personas en edad productiva, intentan conseguir ingresos para satisfacer principalmente la necesidad de alimentación y tienen el deseo de mejorar su situación social, en la que visualizan su mejora como tener un espacio más amplio para vivir y poseer artefactos que les permitan solventar las necesidades de la vida diaria tales como preparar la comida, conservar los alimentos, tener ratos de ocio y entretenimiento (servicio de televisión por cable) y sobrellevar las altas temperaturas de la ciudad. No obstante, en el caso del hijo de doña Beatriz y de su sobrino, a pesar de estar en una edad en la que pueden desarrollar actividades de recreación y formación en los centros de desarrollo que están a unas calles de su vivienda, pasan una parte importante de su tiempo conviviendo con sus amigos en el espacio público, en los parques cercanos o en las aceras.

Por lo tanto, en estas familias sus condiciones espaciales, económicas y sociales se combinan con las decisiones personales de sus integrantes, dando como resultado un sistema familiar en donde la pobreza puede bien asentarse o encontrar ciertas salidas. En el estado neoliberal mexicano esta observación adquiere relevancia, debido a que se ha tendido a estigmatizar a los "pobres" como personas con pocos deseos de superación y en el existe la idea generalizada de que su situación es resultado de una decisión personal". En "el neoliberalismo ... es el individuo y su capacidad de obtener beneficios materiales, la instancia a partir de la cual la sociedad genera progreso y desarrollo..., la pobreza y la enfermedad aparecen aquí como el producto del fracaso individual y la solución es el incremento de la productividad y la competencia" (Rodríguez, 2004, p. 43). Sin embargo, en las familias estudiadas, los individuos que trabajan a pesar de insertarse en la economía con largas jornadas de trabajo (de ocho de la mañana a seis de la tarde), sus ingresos son limitados, teniendo pocas posibilidades de acceder a satisfactores sociales, productos y servicios que ofrece la ciudad y que son asequibles para otras poblaciones en Mérida, tales como ir al cine y pagar un vehículo o una bicicleta, situaciones que también llevan a cuestionar sobre hasta qué punto las decisiones individuales pueden modificar la cultura aprendida y que se ha construido como una reacción, a partir de unas estructuras violentas, que han segregado a grupos y personas que no han alcanzado "el desarrollo", prometido por el sistema neoliberal y el capitalismo, adoptado por México y por Mérida, en particular. 
Asimismo, esto nos invita a reflexionar sobre lo que se considera pobreza en esta ciudad, sobre "las promesas de libertad y de felicidad" (Rodríguez, 2004, p. 42) que la modernidad ha hecho a las sociedades que han implementado el modelo democrático liberal, como lo ha hecho Mérida.

Por otra parte, para Sen (2000), las capacidades permiten que una persona pueda ejercer sus libertades básicas y éstas pueden estar influenciadas o determinadas o no por la renta, existiendo pobreza real (cuando no hay un desarrollo de las capacidades). Aplicando este supuesto en las familias, si bien el ingreso se distribuye entre las personas que la integran, algunos de sus miembros están ejerciendo capacidades sin necesariamente recibir una renta e incluso se puede decir, que están limitando el desarrollo de las capacidades de otros integrantes y consumir, una mayor parte de los ingresos que entran al hogar que el resto, principalmente de la persona que los genera. Por lo adquiere relevancia, analizar en los diagnósticos de pobreza cómo se distribuye el ingreso dentro de los miembros de la familia, su nivel de aprovechamiento y las capacidades que pueden desarrollar cada integrante con y sin recibir una renta.

Asimismo, se destaca que las personas que no contribuyen con un ingreso monetario a la familia, realizan las tareas que sostienen a esta unidad, al mismo tiempo que les permite ejercer ciertas libertades como el ocio, el entretenimiento y la convivencia social, que en el mundo neoliberal son tan necesarias para la cohesión y el reforzamiento del tejido social dentro de las familias y comunidades, por lo que en términos de la profesión, el reto está en cómo potencializar y direccionar este recurso para la mejora en un primer nivel de estos integrantes y en un segundo plano, de la colonia, incluso se abre la posibilidad de que estas personas dada su disponibilidad de tiempo, pudieran participar como líderes comunitarios.

De igual forma, la educación libre de manipulación constituye un recurso fundamental para que una persona en condición de pobreza pueda explorar posibilidades de desarrollo social y humano, esto exige un trabajo colaborativo que involucra horizontalmente al trabajador social con el agente. Es justo en este campo en donde se encuentra el potencial de acción y diagnóstico del Trabajo Social, en la que la actuación del profesional está centrada en el fomento de las relaciones humanas y el cual permite trazar nuevos caminos de su intervención y acercamiento, a partir de reconocer que se comparte con el intervenido o el usuario, una realidad de precariedad laboral, de salarios bajos, con altos niveles de estrés y una esfera de incertidumbre económica y social (loakimidis, 2020).
Resignificar la intervención como un proceso de cambio que se construye de forma bidireccional "al mismo tiempo que se aprecie la importancia de la estructura social y política más amplia" (Loakimidis, 2021, p. 37), constituye una base ontológica y de acción, detonadora del desarrollo de las capacidades de cada individuo que conforma la familia. Esto también lleva a reconocer la labor de la profesión en las diversas instituciones y la urgencia de impulsar un Trabajo Social comunitario activo y presente en las calles, en las familias y en los centros de desarrollo de la organización civil y gubernamental, partiendo de identificar las necesidades, las potencialidades y recursos de cada agente, al mismo tiempo que se coordinen los esfuerzos de cada institución para crear un plan de intervención de cimientos claros que trabaje de forma integral, las diversas aristas que componen el fenómeno de la pobreza, sus aspectos socio-políticos, económicos y ambientales.

Por ello, la presencia del Trabajo Social se vuelve un requisito indispensable para todas las instituciones. Si bien existen programas gubernamentales y acciones por parte de las organizaciones civiles, éstas parecen desvinculadas de algunos individuos de las familias estudiadas que son potenciales beneficiarios. Asimismo, un aspecto importante para el cambio o mejora de estas familias, sería trabajar el desarrollo de una autoestima funcional a nivel individual, en la que cada persona pueda reconocerse como merecedora de sus logros.

Finalmente, la familia como grupo, es la unidad básica de atención en la problemática de la pobreza, ya que es el lugar en donde se consolida el ser humano y aprende la ideología y los valores que le servirán para interactuar con el resto de la sociedad, así como representa, el sitio físico en donde se pueden apreciar de forma más completa y a detalle, las condiciones y las dinámicas sociales que intervienen para que una persona asuma actitudes, pensamientos y acciones que perpetúen un estilo de vida que reproduce la pobreza o bien la inhibe.

\section{CONCLUSIONES}

La pobreza en las dos familias de la colonia EZS II es una estrategia de vida para sobrevivir en condiciones con escasos recursos sociales y económicos, así como es el resultado de un fenómeno de segregación iniciado con la incorporación de México a la globalización, al capitalismo y al modelo neoliberal. Esta también se manifiesta en un conjunto de sentimientos y conductas que conllevan una fuerte carga social que se construye desde afuera y desde adentro de la localidad. Así, aunque los miembros de estas familias, no necesa- 
riamente se identificaron en pobreza, han podido hacer poco al respecto, ya que su tiempo y esfuerzo está dedicado al trabajo diario y no a un plano de acción política, que los lleve a exigir y luchar por mejores condiciones para su colonia.

Asimismo, los integrantes de ambas familias reproducen los patrones de conducta y las actividades económicas que llevaban a cabo sus familias de origen. En la familia de origen, los padres y demás familias han asignado valores a las actividades que se debían realizar y las que no. Por ejemplo, emplearse en un trabajo remunerado ocupa un lugar primordial dentro de la familia, por encima de la educación formal y la salud, en los que estos últimos incluso pueden llegar a considerarse un privilegio. En este sentido y en el marco de un sistema que ha aminorado las responsabilidades del Estado, las actividades del trabajador social deben de concentrarse en modificar estas conductas a través de intervenciones de tipo psico-social, en donde se pueda trabajar junto con el sujeto su proyecto de vida, el cual contemple su historia personal, su contexto inmediato y las valoraciones que este puede hacer sobre su propia existencia como en el caso de doña Greta, así como en facilitar a las familias herramientas para la toma de decisiones, tales como información sobre sus derechos humanos, sobre los programas y apoyos municipales, estatales y federales a los que pueden acceder, al mismo tiempo de que el profesional reconoce y se sensibiliza de la diversidad, las limitaciones y las posibilidades de los integrantes de la familia, de su intervención y de su propia condición como profesionista en un contexto de precariedad, pero en donde también nace y se cultiva la esperanza.

\section{REFERENCIAS BIBLIOGRÁFICAS}

Ander-Egg, E. (2011). Humanismo y Trabajo Social. Interacción y Perspectiva, 1(2), 142-151. https://produccioncientificaluz.org/index.php/interaccion/article/view/476/475

Bolio, J. (2014). Mérida metropolitana. Evolución histórica y rasgos actuales: una perspectiva urbana en R. López y L. A. Ramírez (Eds.), Crecimiento urbano y cambio social: escenarios de transformación de la zona metropolitana de Mérida, (pp. 21-60). Mérida: Universidad Nacional Autónoma de México.

García, C. y Ruiz, O. T. C. (2011). La segregación territorial y el rezago en el sur de la ciudad de Mérida, como el resultado del crecimiento urbano descontrolado. Quivera, 13(1), 122-138. https://www.redalyc.org/ pdf/401/40118420007.pdf

Hernández, R., Fernández, C., \& Baptista, M. del P. (2010). Metodología de la investigación (5ta. Ed.). McGraw-Hill.

loakimidis, V. (2021). Trabajo social en el contexto neoliberal global: solidaridad y resistencia desde una perspectiva radical. Propuestas Críticas en Trabajo Social - Critical Proposals in Social Work, 1(1), 28-42. 10.5354/27356620.2021.61229. https://nuevosfoliosbioetica.uchile.cl/ index.php/RPCTS/article/view/61229/65105

Lewis, O. (1964). Los hijos de Sánchez. Autobiografía de una familia mexicana. México: Fondo de Cultura Económica.

Martínez, M. (2006). Ciencia y arte en la metodología cualitativa. México: Trillas.

Naciones Unidas (s.f.). Desafíos globales: Acabar con la pobreza. https://www.un.org/es/global-issues/ending-poverty

Pérez, S. (2011). Políticas públicas de combate a la pobreza en Yucatán, 1990-2006. Gestión y Política Pública, 20(2), 291-329. http://www.scielo.org.mx/pdf/gpp/v20n2/ v20n2a3.pdf

Rodríguez, F. (2004). La pobreza como un proceso de violencia estructural. Revista de Ciencias Sociales (RCS), (1), 4250. https://www.flacsoandes.edu.ec/sites/default/files/ agora/files/1278089538.francisco_rodriguez.pdf

Secretaría de Bienestar (2020). Informe anual sobre la situación de pobreza y rezago social 2020. Yucatán, Mérida. https://extranet.bienestar.gob.mx/pnt/Informe_2020/inf_ municipal_31050.pdf

Sen, A. (2000). La pobreza como privación de capacidades. En, Desarrollo y Libertad (pp. 114-141). Buenos Aires: Editorial Planeta S. A.

Valero, A. (1994). El Trabajo Social en México: Desarrollo y Perspectivas. México: UNAM. 